\title{
Improved Removal Capacity and Equilibrium Time of Maghemite Nanoparticles Growth in Zeolite Type 5A for $\mathrm{Pb}$ (II) Adsorption
}

\author{
Juan A. Ramos-Guivar ${ }^{1, * \mathbb{C}}$, Katterine Taipe ${ }^{1}$, Miguel Angelo Schettino, Jr. ${ }^{2}$, Eloi Silva ${ }^{3}$, \\ Marco Antonio Morales Torres ${ }^{4}$, Edson Caetano Passamani ${ }^{2}$ and Fred Jochen Litterst ${ }^{5,6}$ \\ 1 Departamento de Física del Estado Sólido (DAFES), Facultad de Ciencias Físicas, Universidad Nacional \\ Mayor de San Marcos, P.O. Box 14-0149, Lima 14, Peru; katterine.taipe@unmsm.edu.pe \\ 2 Department of Physics, Federal University of Espírito Santo-UFES, Vitória, ES 29075-910, Brazil; \\ miguel.ufes@gmail.com (M.A.S.J.); passamaniec@yahoo.com.br (E.C.P.) \\ 3 Department of Chemistry, Federal University of Espírito Santo-UFES, Vitória, ES 29075-910, Brazil; \\ eloi.silva@ufes.br \\ 4 Department of Theoretical and Experimental Physics, Federal University of Rio Grande do Norte-UFRN, \\ Natal, RN 59078-970, Brazil; marco.moralestorres@gmail.com \\ 5 Institut für Physik der Kondensierten Materie, Technische Universität Braunschweig, \\ 38110 Braunschweig, Germany; j.litterst@tu-bs.de \\ 6 Centro Brasileiro de Pesquisas Físicas, Rio de Janeiro, RJ 22290-180, Brazil \\ * Correspondence: juan.ramos5@unmsm.edu.pe
}

Received: 21 March 2020; Accepted: 7 April 2020; Published: 26 August 2020

\begin{abstract}
Novel magnetic zeolite type 5A nanocomposites were synthesized by the co-precipitation method and applied to lead removal from aqueous ambient. Maghemite nanoparticles were mixed with zeolite and, by controlling its content, transmission electron microscopy results gave sizes of 5 to $15 \mathrm{~nm}$ and selected area electron diffraction patterns confirmed the presence of zeolite. The nanocomposites have high specific surface area with values up to $194 \mathrm{~m}^{2} / \mathrm{g}$. Magnetization measurements proved superparamagnetic behavior with saturation values of $\sim 35 \mathrm{emu} / \mathrm{gFe}$. Kinetic adsorption experiments showed removal efficiencies of $99.9 \%$ and an enhanced equilibrium time of $5 \mathrm{~min}$. The lead concentrations after adsorption experiments lay under the permissible levels of $10 \mu \mathrm{g} \mathrm{L}^{-1}$, according to the World Health Organization. The maximum adsorption capacity, estimated by Sips model, was $265 \mathrm{mg} \mathrm{L}^{-1}$ at $300 \mathrm{~K}$. The removal efficiency was significantly improved in the range of $\mathrm{pH}>6$, as well as in the presence of cation interferents such as $\mathrm{Ca}(\mathrm{II}), \mathrm{Cu}(\mathrm{II})$, and $\mathrm{Cd}(\mathrm{II})$. The adsorption mechanism was explained with cation exchange between $\mathrm{Pb}(\mathrm{II})$, the zeolite framework, and the protonated maghemite surface. Besides, our system revealed recyclability even after seven regeneration cycles. Thus, our synthesized materials have remarkable adsorption properties for lead water remediation processes.
\end{abstract}

Keywords: maghemite; zeolite type 5A; lead removal; water treatment

\section{Introduction}

Polluted water often presents non-biodegradable effluents like heavy metals and organic materials, which are toxic and can cause several illnesses [1,2]. Nowadays, drinking water is systematically contaminated, for example, by several heavy metals from different sources. Contamination of water with lead $(\mathrm{Pb}(\mathrm{II}))$ may be the result of the water contact with household plumbing systems that contain lead devices; bad manipulation of lead-acid batteries; disasters in mining companies; and, of course, illegal mining [3]. The permissible concentration level of lead in water is $10 \mu \mathrm{g} \mathrm{L}-1$ according to World 
Health Organization (WHO) guidelines [3]. Excess ingestion can provably cause health problems like mental retardation as well as kidney and brain diseases [3,4]. Therefore, in this current context, several lead separation methods (e.g., electrochemical treatments, membrane filtration, and chemical precipitation) have been developed and applied to improve the water quality from different sources [5]. Among these methods, the adsorption process is highly advantageous owing to its reproducibility, cost-effective implementation, and relative simplicity in possible commercial applications [6].

One of the most suitable materials for application in the adsorption process is zeolites, having interesting catalytic and adsorbent properties $[7,8]$. This class of materials is composed of crystalline aluminum-silicate and alkali earth elements like sodium and calcium [7], keeping the stoichiometric formula $M_{\frac{x}{n}}\left[\left(\mathrm{AlO}_{2}\right)_{x}\left(\mathrm{SiO}_{2}\right)_{y}\right] z \mathrm{H}_{2} \mathrm{O}$, where $x$ and $y$ are integer numbers, $n$ represents the valence of cation $\mathrm{M}$, and $z$ is related to the number of water molecules in the unit cell. They can be divided into natural and synthetic zeolites. Among all-natural families of zeolites, 40 species are found [8]. In addition, there exist about 150 types of synthesized zeolites, which are designated with a specific letter: Type A, Type X, Type Y, Type ZSM, and so on [8]. They differ in the pore size, specific surface area, and positive cations that balance the molecules and influence the pore diameters and adsorptive properties [8]. Moreover, it should be said that zeolites have been used as adsorbents for organic and metal pollutants $[7,9]$. In general, they have demonstrated excellent cation-exchange selectivity for heavy metals owing to their featured porous properties and chemical composition [7].

On the other hand, Fe-oxide based nanoadsorbents present mesoporous and chemical surface configurations that can also favor the adsorption of metal cations [10]. Additionally, iron oxide nanoparticles (NPs) are low-cost and environmentally friendly materials. Thus, these Fe-oxide NPs can be combined with other adsorbents to improve the adsorption and magnetic separation processes [11]. For instance, systems based on magnetic nanoparticles coated montmorillonite [12], core-shell gold coated magnetic nanoparticles [13], iron-based nanoparticles-zeolite composites [14], zero valent iron [15], Co-doped $\mathrm{Fe}_{2} \mathrm{O}_{3}$ [16], MNPs@carboxymethylated biopolymers [17], and the composite of solid matrices with iron oxides have been proposed as good candidates for bioremediation processes [18]. To our knowledge, however, a magnetic nanocomposite made of maghemite and zeolite type 5A has not been studied and tested for lead removal. So, in this work, we have prepared ferromagnetic zeolite composites using maghemite NPs as precursor that were mixed with mesoporous zeolite type 5A, controlling their contents. Synthesis experiments were performed to obtain the optimum material for $\mathrm{Pb}(\mathrm{II})$ adsorption and to be magnetically removed with an applied field. The crystal structure, sample surface, and their magnetic properties were systematically studied by X-ray diffraction, $\mathrm{N}_{2}$ adsorption-desorption, and vibrating sample magnetometry (VSM) measurements. Their application as magnetic adsorbents was tested for $\mathrm{Pb}$ (II) removal from synthetic aqueous solution up to lead concentrations reaching value below the quantification limits of inductively coupled plasma atomic emission spectroscopy (ICP-OES). We conclude that combining zeolite adsorption and magnetic separation properties facilitates the removal of lead from contaminated water easily, making our nanocomposite a promising material that is suitable for water remediation in effluents with high lead contents.

\section{Materials and Methods}

\subsection{Materials and Chemicals}

The following chemical compounds of analytical grade, obtained from Sigma Aldrich (São Paulo, Brazil), were used without further purification: iron sulfate hepta hydrated $\left(\mathrm{FeSO}_{4} \cdot 7 \mathrm{H}_{2} \mathrm{O}\right)$, iron(III) chloride anhydrous $\left(\mathrm{FeCl}_{3}\right)$, ammonia hydroxide $\left(\mathrm{NH}_{4} \mathrm{OH}, 28-30 \%\right)$, and zeolite type $5 \mathrm{~A}$. Lead nitrate, $\mathrm{Pb}\left(\mathrm{NO}_{3}\right)_{2}$, from Dinâmica (São Paulo, Brazil), was used. 


\subsection{Adsorbent Synthesis}

The co-precipitation method is suitable to obtain high quantities in term of mass for desired industrial scalability. It consists in mixing iron precursors $(\mathrm{Fe}(\mathrm{II}) / \mathrm{Fe}(\mathrm{III})=0.5 \mathrm{ratio}$, an optimum ratio that favors spherical NPs in high alkaline medium ( $\mathrm{pH}=10-12)$. It should be also mentioned that (i) solid separation and washing procedures are easy to handle using magnetic separation protocol and (ii) the zeolite content was modified in the synthesis to obtain the optimum nanoadsorbent for $\mathrm{Pb}(\mathrm{II})$ adsorption. Specifically, we prepared zeolite type 5A composites using three different synthesis processes, which are individually described below.

\subsubsection{Synthesis 1}

An amount of $0.5 \mathrm{~g}$ of the zeolite type $5 \mathrm{~A}$ was dispersed with distilled water $(50 \mathrm{~mL})$ in a glass cylinder container (beaker) and left to stir for $30 \mathrm{~min}$. Then, $6 \mathrm{~g}$ of $\mathrm{FeCl}_{3}(37 \mathrm{mmol})$ and $5.1 \mathrm{~g}$ of $\mathrm{FeSO}_{4} \cdot 7 \mathrm{H}_{2} \mathrm{O}(18.5 \mathrm{mmol})$ were added to this dispersion. Immediately after the first step, a solution of $\mathrm{NaOH}(1.5 \mathrm{M})$ solution was dropped to the mixture till a black color covered the total solution, as a result of NPs formation. The $\mathrm{pH}$ of the solution was set to 10 . The chemical reaction was left at $80 \pm 2{ }^{\circ} \mathrm{C}$, for $6 \mathrm{~h}$. After that, we cooled the reaction and the material was washed several times and separated with the help of magnetic decantation. This sample was labeled as NPZEO1.

\subsubsection{Synthesis 2}

A weighted amount of $0.5 \mathrm{~g}$ of the zeolite type $5 \mathrm{~A}$ was dispersed in distilled water $(50 \mathrm{~mL})$ for $30 \mathrm{~min}$ under vigorous stirring. In sequence, $6 \mathrm{~g}$ of $\mathrm{FeCl}_{3}(37 \mathrm{mmol})$ and $5.1 \mathrm{~g}$ of $\mathrm{FeSO}_{4} \cdot 7 \mathrm{H}_{2} \mathrm{O}$ (18.5 mmol) were added to the previous dispersion. A Fe(II)/Fe(III) molar ratio equal to 0.5 was used (spherical particles were expected under this condition). Subsequently, $\mathrm{NH}_{4} \mathrm{OH}(30 \%)$ was added dropwise to the dispersion until the value of $\mathrm{pH}$ has reached 10. A black precipitate formed as a characteristic of iron oxide NPs formation in alkaline medium. The chemical reaction was left at $80 \pm 2{ }^{\circ} \mathrm{C}$, for $6 \mathrm{~h}$. After cooling the reaction, the material was washed several times and, using magnetic decantation, it was separated. This sample was labeled as NPZEO2.

\subsubsection{Synthesis 3}

An amount of $2.5 \mathrm{~g}$ of the zeolite type $5 \mathrm{~A}$ was dispersed in distilled water $(300 \mathrm{~mL})$ in a beaker for $30 \mathrm{~min}$ under vigorous stirring. After that, $1.6 \mathrm{~g}$ of $\gamma-\mathrm{Fe}_{2} \mathrm{O}_{3} \mathrm{NPs}$ prepared by co-precipitation (same conditions as synthesis 1) was added in the previous dispersion at room temperature (RT), for $24 \mathrm{~h}$. The $\mathrm{pH}$ of the dispersion was neutral. Thereafter, the sample was filtered with a $2 \mu \mathrm{m}$ membrane filter to remove the excess of NPs that had not precipitated or/and interacted with the zeolite matrix. Finally, the sample was dried in an oven for $36 \mathrm{~h}$. We refer to this sample as NPZEO3.

\subsection{Characterization of Structural, Surface Area, and Magnetic Properties}

The X-ray diffraction (XRD) data were collected using a Bruker D8 diffractometer, operating with $\mathrm{Cu}$ $\mathrm{K} \alpha$ radiation $(1.5406 \AA)$, at $50 \mathrm{kV}$ and $100 \mathrm{~mA}$. Powder X-ray diffraction (XRD) patterns were obtained in step scanning mode, $2 \theta=8-80^{\circ}$ with a step of $0.01^{\circ}$. The crystallographic information file (CIF) given by the software Match V3 (version 3, Crystal Impact, Bonn, Germany) [19] was \#9006316 for maghemite and \#9002158 for goethite. The $\gamma-\mathrm{Fe}_{2} \mathrm{O}_{3}$ crystallographic parameters obtained by Pecharroman et al. [20] were used as initial refinement parameters (cubic, space group $\mathrm{Fd} \overline{3} \mathrm{~m}, \mathrm{a}=8.33 \AA$ ). For goethite, the crystallographic parameters obtained by Gualtieri were used (orthorhombic, space group Pnma, $\mathrm{a}=9.91 \AA, \mathrm{b}=3.01 \AA, \mathrm{c}=4.58 \AA$ ) [21]. The CIF for the zeolite was \#2102130, the space group was F $\overline{4} 3 \mathrm{c}$, cubic, and $\mathrm{a}=24.5 \AA$ [22]. For the quantitative analysis in the composites, the scale factor was related 
to the weight fraction of each crystallographic phase, $\mathrm{W}_{\mathrm{j}}$ [23]. The degree of crystallinity (DOC) was estimated from the XRD pattern according to the following [24]:

$$
\operatorname{DOC}(\%)=\frac{\text { Area of crystalline peaks }}{\text { Area of (crystalline }+ \text { amorphous }) \text { peaks }} \times 100
$$

Transmission electron microscopy (TEM) images and selected area electron diffraction (SAED) patterns were obtained using a JEOL-JEM2100 microscope (Tokyo, Japan). Nitrogen $\left(\mathrm{N}_{2}\right)$ adsorptiondesorption measurements isotherms at $77 \mathrm{~K}$ were measured with Autosorb-1 equipment. Before the recording of the data, the samples were degassed at $130{ }^{\circ} \mathrm{C}$ for $6 \mathrm{~h}$. Then, the textural properties, including surface specific area (SSA) and pore size distribution (PSD), were determined by employing a multi-Brunauer-Emmett-Teller (BET) point plot and the non-local density functional theory (NLDFT) model [25]. This last method is suitable for the applicable pore diameter range of 0.35 to $35 \mathrm{~nm}$. The carbon kernel file at $77 \mathrm{~K}$, based on a slit-pore model and on a cylindrical pore model, was used to obtain the pore size distribution of the functionalized NPs. The physical properties measurement system (PPMS Dynacool, Quantum Design Latin America, San Diego, CA, USA) equipped with a vibrating sample magnetometer from quantum design was used to obtain magnetic hysteresis $(\mathrm{M}-\mathrm{H})$ loops at RT and $5 \mathrm{~K}$. Zero field cooling (ZFC) and field cooling (FC) protocols were done to record magnetization data in the temperature range from 5 to $300 \mathrm{~K}$ under a probe field of $70 \mathrm{kOe}$.

\subsection{Heavy Metal Adsorption Experiments}

The synthetic aqueous solutions of lead were prepared from $\mathrm{Pb}\left(\mathrm{NO}_{3}\right)_{2}$. The adsorption kinetic experiments, influence of $\mathrm{Pb}$ concentration, and adsorbent mass were conducted at $\mathrm{pH}=6$. The batch kinetic experiments were carried out by stirring $25 \mathrm{mg}$ of adsorbent with $50 \mathrm{~mL}$ of a $50 \mathrm{mg} \mathrm{L}^{-1}$ initial $\mathrm{Pb}$ (II) solution at $25^{\circ} \mathrm{C}$ for intervals of $5 \mathrm{~min}$ to $4 \mathrm{~h}$. After finding the equilibrium adsorption time, the adsorption isotherm was obtained from an initial $\mathrm{Pb}$ (II) solution of $130 \mathrm{mg} \mathrm{L}^{-1}$. Subsequent dilutions were done to obtain the total isotherm, keeping the same dosage of $0.5 \mathrm{~g} \mathrm{~L}^{-1}$. The adsorbent dose was tested by varying the adsorbent amount $(5,10,15,25$, and $50 \mathrm{mg})$ in contact with $50 \mathrm{~mL}$ of $\mathrm{Pb}$ (II) solution. The batch adsorption experiments were carried out under continuous shaking at $150 \mathrm{rpm}$ and at RT, for $1 \mathrm{~h}$. For speed agitation experiments, speed ranges of 50 to $500 \mathrm{rpm}$ were employed. An adsorbent mass of $25 \mathrm{mg}$ and an initial volume of $50 \mathrm{~mL}$ were used at RT. For the determination of the $\mathrm{pH}$ dependence of the adsorbed amount, an initial concentration of $70 \mathrm{mg} \mathrm{L}^{-1}$ was used, and the $\mathrm{pH}$ was changed using $\mathrm{HCl}(0.01 \mathrm{M})$ and $\mathrm{NaOH}(0.1 \mathrm{M})$ solutions. The initial $\mathrm{pH}$ slightly differs from the equilibrium one (5.8-5.9), but, in first approximation, it can be assumed to be equal to 6 for the experiments. The $\mathrm{pH}$ equilibrium value was measured in all the experiments. The quantification of lead concentrations was done by ICP-OES (inductively coupled plasma atomic emission spectroscopy). A Perkin Elmer Optima 7000 DV spectrometer (Waltham, MA, USA) was used for measurements after calibration with stock solutions. The adsorbed lead amount was calculated by the difference between the initial $\left(C_{0}\right)$ and final $\left(C_{t}\right)$ concentrations in solutions. The adsorbed amount is defined as follows:

$$
q_{t}=\frac{\left(C_{0}-C_{t}\right) V}{m}\left(\mathrm{mg} \mathrm{g}^{-1}\right)
$$

where $q_{t}$ is the amount, in $\mathrm{mg}$, of adsorbate adsorbed per gram of adsorbent for a certain time $t$; the parameter $m$ is the adsorbent mass $(\mathrm{mg})$; and $V(\mathrm{~mL})$ is the reservoir volume used for batch adsorption tests.

To compare the kinetic and isotherm adsorption models, we used the Akaike's information criterion (AIC). The best fit to the experimental data has the lowest value of AIC [26].

$$
A I C=N \ln \left(\frac{S S E}{N}\right)+2 N_{p}+\frac{2 N_{p}\left(N_{p}+1\right)}{N-N_{p}-1}
$$


where $N$ corresponds to the number of experimental data, $N_{p}$ is the number of parameters in the respective model, and SSE is the sum square error given by the following:

$$
S S E=\sum_{t=0}^{t}\left(q_{t, \exp }-q_{t, \text { model }}\right)^{2}
$$

where $q_{t, \text { exp }}$ and $q_{t, \text { model }}$ are the adsorption capacities, respectively, calculated from the experimental data at the equilibrium time and from the respective kinetic and isotherm models.

\section{Results and Discussion}

\subsection{Structural and Morphological Properties}

Several phenomenological models were systematically applied to study the microstructural parameters obtained from XRD patterns of the samples. In this sense, it is important to mention that the physical information of the XRD pattern of a particular sample must be firstly corrected using the instrumental broadening correction, according to Equation (4) below:

$$
\beta_{D}^{2}=\left[\left(\beta^{2}\right)_{\text {measured }}-\left(\beta^{2}\right)_{\text {inst }}\right]
$$

where $\beta_{D}$ corresponds to instrument-corrected broadening of the XRD pattern.

Thus, the simplest and most common method to estimate the average crystalline grain sizes is the Scherrer's formula, given by the following:

$$
D=\frac{k \lambda}{\beta_{D} \cos \theta}
$$

where $k=0.94 \mathrm{~nm}^{-1}$ for spherical shape morphologies [27], $\lambda$ corresponds to $\mathrm{Cu} \mathrm{K} \alpha$ radiation's wavelength, $\beta_{D}$ is peak broadening (Equation (4)), and $\theta$ is the angular peak position. Then, a linear plot of $\cos \theta$ versus $1 / \beta_{D}$ can be fitted and the slope of the curve is related to the average grain size, as shown by the results in Figure S1 (Supplementary Material). The calculated grain size values are reported in Table S1. The zeolite type $5 \mathrm{~A}$ has an average grain size of $66 \mathrm{~nm}$, the maghemite in the NPZEO1 sample has a grain size of $11.2 \mathrm{~nm}$, and the goethite an average size of $58.9 \mathrm{~nm}$. The NPZEO2 sample presents only one crystalline phase of maghemite with an average size of $16.8 \mathrm{~nm}$, while the NPZEO3 sample displays a presence of two phases: zeolite type 5A with grains of $112.3 \mathrm{~nm}$ and maghemite with average sizes of $7.8 \mathrm{~nm}$.

On the other hand, the Scherrer's estimation does not consider the internal strain in the crystalline grains provoked by crystal imperfections and local distortions of the lattice. However, the strain parameter is included in the Williamson-Hall's (W-H) method [27]:

$$
\beta_{h k l} \cos \theta=\left(\frac{k \lambda}{D}\right)+(4 \varepsilon \sin \theta)
$$

where $\varepsilon(\%)$ is the induced strain of crystalline lattice. Equation (3) represents the uniform deformation model (UDM), which assumes the strain uniform in all crystallographic directions [27]. By contrary, the uniform strain deformation model (USDM) is a more generalized perspective, as it includes Hooke's law and refers to strain in the W-H by introducing $\sigma=Y_{\varepsilon}$, where $\sigma$ is the crystal's stress and the quantity $Y$ is the Young's modulus. So, we can rewrite Equation (6) as follows:

$$
\beta_{h k l} \cos \theta=\left(\frac{k \lambda}{D}\right)+\left(\frac{4 \sigma \sin \theta}{Y_{h k l}}\right)
$$


For a cubic crystal, the Young's modulus can be calculated using the following [28]:

$$
Y_{h k l}=\frac{9 B_{0} G_{V}}{3 B_{0}+G_{V}}
$$

where

$$
\begin{gathered}
G_{V}=\frac{1}{5}\left(3 C_{44}+2 C^{\prime}\right) \\
C^{\prime}=\frac{1}{2}\left(C_{11}-C_{12}\right) \\
C_{11}+2 C_{12}=3 B_{0}
\end{gathered}
$$

are the elastic constants of cubic crystals and the constants $C_{44}=71.0, C_{11}=380.0$, and $C_{12}=257.0 \mathrm{GPa}$ were obtained from computational calculations [28]. The value obtained for $Y_{h k l}$, by substituting Equations (9)-(11) into Equation (8), is $187.5 \mathrm{GPa}$ (this value will be substituted into Equation (7) or (13)). On the other hand, the uniform deformation energy density model (UDEDM) takes into account the following [27]:

$$
\beta_{h k l} \cos \theta=\left(\frac{k \lambda}{D}\right)+\left(4 \sin \theta\left(\frac{2 U}{Y_{h k l}}\right)^{1 / 2}\right)
$$

where the energy density, $U$, is defined as $U=\frac{\left(\varepsilon^{2} Y_{h k l}\right)}{2}$, where $\sigma=\varepsilon Y$ can be expressed by the following:

$$
U=\frac{\left(\varepsilon^{2} Y_{h k l}\right)}{2}=\left(\frac{\sigma^{2}}{2 Y_{h k l}}\right)
$$

The average crystallite grain sizes and the parameters $\varepsilon$ and $\sigma$ were estimated by the three models (Figures S2-S4) and have shown similar values for the studied samples, as can be appreciated in Table S1. All these values differ from Scherrer's estimation, and reinforce the idea of strain consideration in the estimation of crystallite grain sizes. One further model that contains the isotropic line broadening is the average size-strain model, where less weight is given to XRD data from Bragg peaks at high angles [27]. The model is represented by the following:

$$
\left(\frac{d_{h k l} \beta_{h k l} \cos \theta}{\lambda}\right)^{2}=\frac{K}{D}\left(\frac{d_{h k l}^{2} \beta_{h k l} \cos \theta}{\lambda}\right)+\left(\frac{\varepsilon}{2}\right)^{2}
$$

where $K=3 / 4$ for spherical particles. A size-strain plot (SSP) of $\left(\frac{d_{h k l} \beta_{h k l} \cos \theta}{\lambda}\right)^{2} \operatorname{versus}\left(\frac{d_{h k l}^{2} \beta_{h k l} \cos \theta}{\lambda}\right)$ gave a particle size from the slope and the root of the y-intercept yields the strain that found that particle (see Figure S5). The $\mathrm{R}^{2}$ values are important to differentiate among all of the studied methods (see Table S1). We obtained only positive values of $\mathrm{R}^{2}$ for all of the crystallographic phases using the size-strain model, suggesting that this model better fits the XRD patterns presented in this study. To have a better understanding of the obtained fitted data, we used the advanced Rietveld method, the refined parameters of which are summarized in Table 1 for all samples. The pure zeolite Type $5 \mathrm{~A}$ had a stoichiometric formula $\mathrm{Ca}_{48} \mathrm{Al}_{96} \mathrm{Si}_{96} \mathrm{O}_{384}$, which corresponds to a dehydrated Ca-A zeolite $(\mathrm{a}=24.6 \AA)$ [22]. Figure 1a shows the Rietveld refined diffractogram for this sample. A mean crystallite diameter of $380 \mathrm{~nm}$ was estimated. In contrast, the NPZEO1 and NPZEO2 samples (Figure 1b,c) display Bragg diffraction peaks in the region from 2 to 80 degrees, corresponding to inverse spinel cubic structure of the $\gamma-\mathrm{Fe}_{2} \mathrm{O}_{3}$ phase [29]. However, additional Bragg peaks with minor contributions to the XRD pattern of the NPZEO1 sample are present and correspond to the goethite phase, according to our Rietveld analysis. 
Table 1. Rietveld refinement parameters of zeolite type 5A, NPZEO1, and NPZEO2 samples using the Fullprof program: cell parameters, cell volume, global average size, and agreement factors. $R_{p}(\%)$ and $R_{w p}(\%)$ are the profile residual and the weighted profile residual factors, respectively, used to verify the Rietveld refinement quality. The goodness of fit, $\chi^{2}$, was equal to $\left(\frac{R_{w p}}{R_{e x p}}\right)^{2}$, where $R_{\exp }$ is the expected profile residual.

\begin{tabular}{|c|c|c|c|c|}
\hline \multirow[t]{2}{*}{ Refined Parameters } & \multirow[t]{2}{*}{ Zeo5A } & \multicolumn{2}{|c|}{ NPZEO1 } & \multirow{2}{*}{$\frac{\text { NPZEO2 }}{\gamma-\mathrm{Fe}_{2} \mathrm{O}_{3}}$} \\
\hline & & $\gamma-\mathrm{Fe}_{2} \mathrm{O}_{3}$ & goethite & \\
\hline a $(\AA)$ & 24.5586 & 8.3506 & 9.9182 & 8.3022 \\
\hline $\mathrm{b}(\AA)$ & 24.5586 & 8.3506 & 3.0059 & 8.3022 \\
\hline$c(\AA)$ & 24.5586 & 8.3506 & 4.5801 & 8.3022 \\
\hline$\alpha\left(^{\circ}\right)$ & 90 & 90 & 90 & 90 \\
\hline$\beta\left(^{\circ}\right)$ & 90 & 90 & 90 & 90 \\
\hline$\gamma\left({ }^{\circ}\right)$ & 90 & 90 & 90 & 90 \\
\hline $\mathrm{V}\left(\AA^{3}\right)$ & $14,811.94$ & 582 & 136.5 & 572 \\
\hline global average size $(\mathrm{nm})$ & 373 & 6.6 & 290 & 10.5 \\
\hline$R_{p}(\%)$ & 16.9 & \multicolumn{2}{|c|}{55} & 53 \\
\hline$R_{w p}(\%)$ & 19.1 & \multicolumn{2}{|c|}{43.8} & 35.7 \\
\hline$R_{\exp }(\%)$ & 16.8 & \multicolumn{2}{|c|}{24.8} & 27.9 \\
\hline$x^{2}$ & 1.3 & \multicolumn{2}{|c|}{3.1} & 1.6 \\
\hline
\end{tabular}

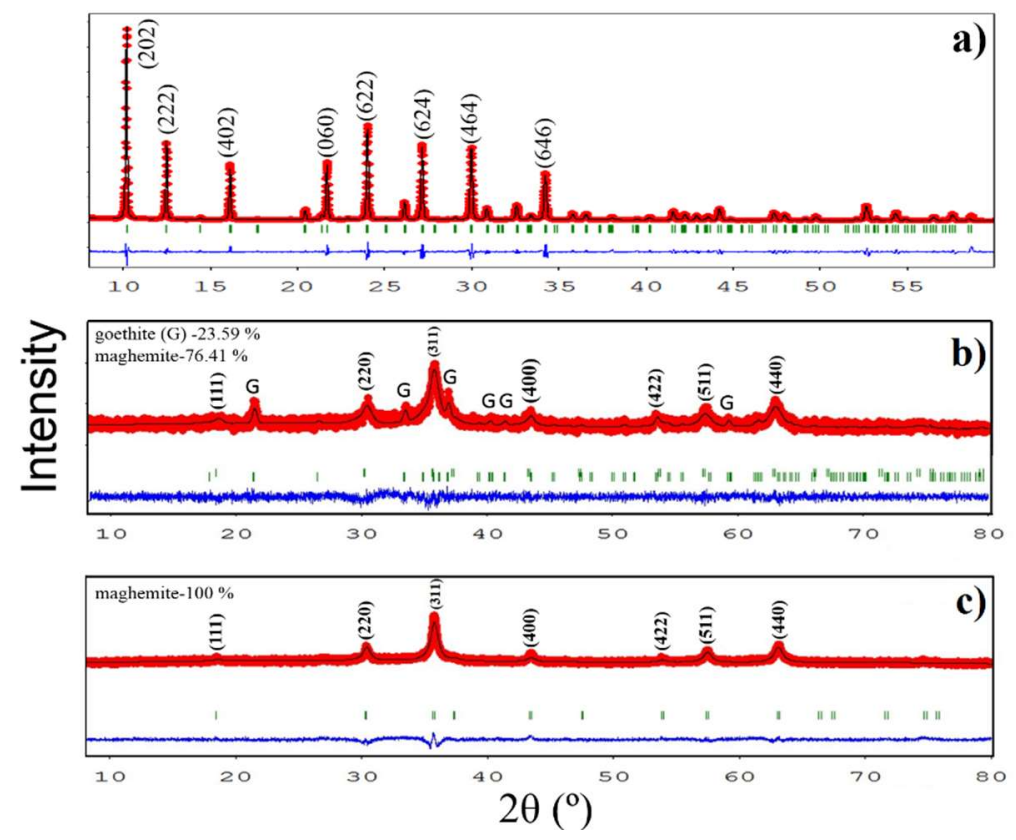

Figure 1. X-ray diffraction (XRD) patterns with their Rietveld refinements for zeolite type 5A (a), NPZEO1 (b), and NPZEO2 (c) samples. The observed experimental diffractograms are given by the red lines $\left(\mathrm{I}_{\mathrm{obs}}\right)$, the black lines $\left(\mathrm{I}_{\mathrm{cal}}\right)$ are calculated diffractograms, and the residual lines are shown in blue color. $\mathrm{G}$ represents goethite phase and Bragg's peak positions are indicated with green vertical bars.

For the NPZEO1 sample, the Rietveld quantitative analysis of the identified crystal phases in the composites gave percentage values of $76 \%$ and $24 \%$ for $\gamma-\mathrm{Fe}_{2} \mathrm{O}_{3}$ and goethite, respectively. The presence of the goethite can be explained by the alkaline base that was used in the synthesis, as previously reported [29]. In fact, the alkaline reactant can severely affect the presence of secondary phases, like iron hydroxides. Moreover, as already expected, no zeolite diffraction peaks were observed in XRD patterns owing to its low concentration (it was used in the synthesis of $0.5 \mathrm{~g}$ of zeolite when compared with the relative high amount of iron reactive). For the NPZEO2 sample, only diffraction peaks of the $\gamma-\mathrm{Fe}_{2} \mathrm{O}_{3}$ NPs were found in the XRD pattern (no trace of goethite was found), indicating that the NPZEO2 
sample is a composite of $\gamma-\mathrm{Fe}_{2} \mathrm{O}_{3}$ NPs and zeolite Type 5A. The mean crystallite size, $\langle D\rangle$, estimated from the refinement for the $\gamma-\mathrm{Fe}_{2} \mathrm{O}_{3}$ phase, was 7.0(5) $\mathrm{nm}$ for the NPZEO1 and 11.0(5) $\mathrm{nm}$ for the NPZEO2. For the NPZEO3 sample (Figure 2a), a major contribution of zeolite (phase percentage of $63 \%$ ) is measured in the XRD pattern, while $\gamma-\mathrm{Fe}_{2} \mathrm{O}_{3}$ Bragg diffraction peaks were observed as a secondary phase (phase percentage of 37\%). A value of $\langle D\rangle=7.8(5) \mathrm{nm}$ was also found using the Scherrer formula, as described above.
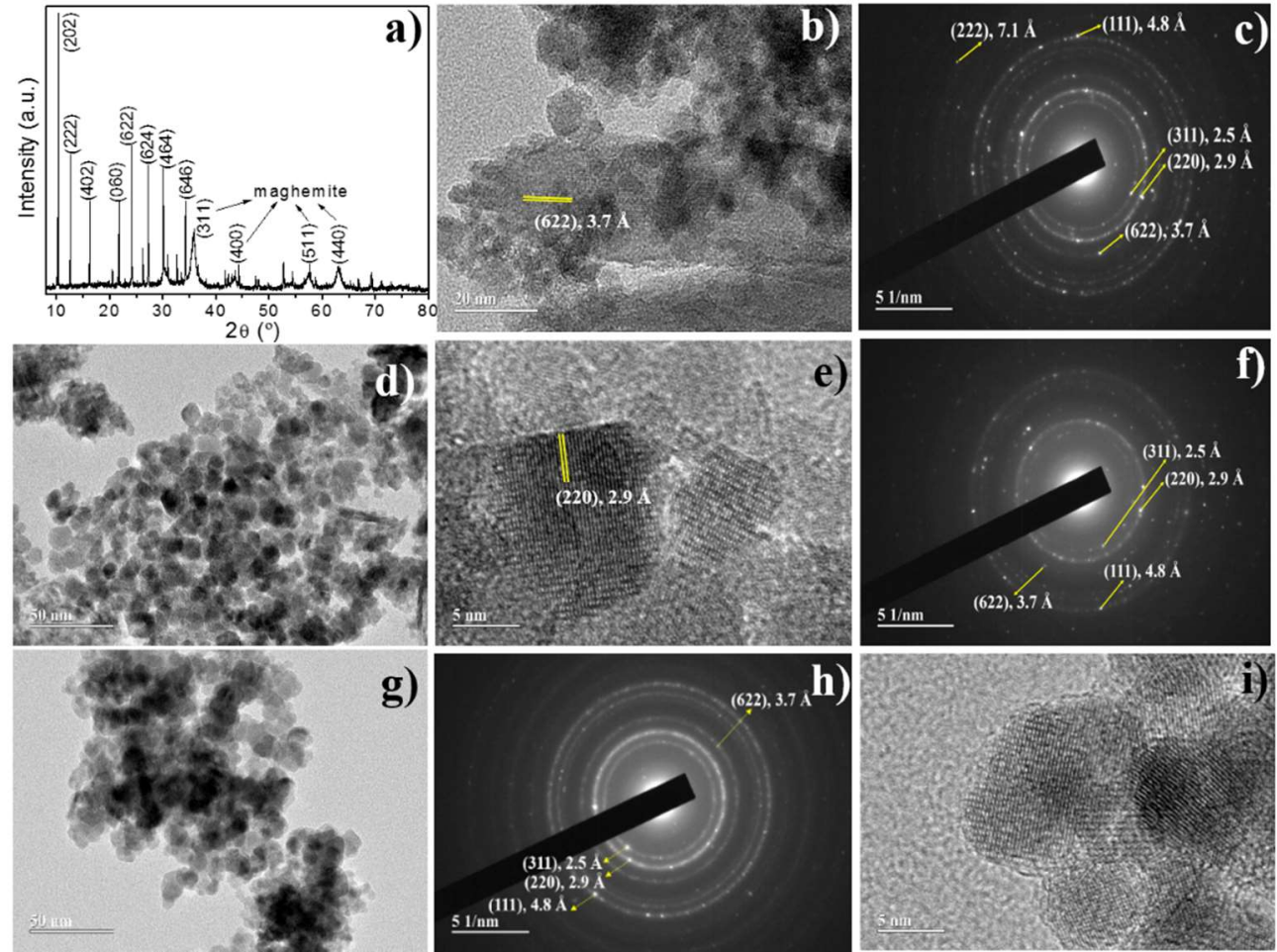

Figure 2. XRD pattern for the NPZEO3 composite, where the Miller indices are also indicated (a). Transmission electron microscopy (TEM) images for the NZPEO1 (b), NPZEO2 (d,e), NPZEO3 (g,i), and their respective selected area electron diffraction (SAED) patterns $(\mathbf{c}, \mathbf{f}, \mathbf{h})$.

The DOC values, estimated from XRD patterns, were $88 \%, 92 \%, 94 \%$, and $89 \%$ for zeolite type $5 \mathrm{~A}$, NPZEO1, NPZEO2, and NPZEO3 samples, respectively. The DOC of pure zeolite did not vary when mixing with maghemite nanoparticles (NPZEO3). Maghemite nanoparticles (NPZEO2) have a high degree of crystallinity, where the presence of goethite in the NPZEO1 sample slightly changes the DOC value. Recent studies $[24,30]$ correlate the effects of the DOC values with the reactivity of the adsorbate, in our case, $\mathrm{Pb}(\mathrm{II})$. However, the big amount of crystalline nanomaghemite, when compared with low dosage of zeolite used in synthesis of the NPZEO1 and NPZEO2 sample, reduces the reactivity of pure zeolite for $\mathrm{Pb}(\mathrm{II})$ uptake. Thus, as proved by quantitative Rietveld analysis, the balance content of zeolite and nanomaghemite will exhibit remarkable adsorption properties for $\mathrm{Pb}(\mathrm{II})$, as will be shown below.

The TEM images (Figure 2b-i) showed, in general, NPs with a broad size distribution with mean diameter sizes of 8.9(3) nm, 8.7(3) nm, and 9.4(3) nm for the NPZEO1, NPZEO2, and NPZEO3 samples, as obtained from pore size distribution fitted to a Gaussian profile (Figure 3b-d). These values differ from those obtained by the previous crystallite analysis methods (Figure 3a), because they do not consider the anisotropic line broadening often found in NPs [31], as the Rietveld method takes into consideration. From the zoomed images (Figure 2e,i), we can see that maghemite NPs form aggregates with zeolites. Moreover, the selected area electron diffraction (SAED) patterns (Figure 2c,f,h) confirm the presence of zeolite in the nanocomposite owing to the interplanar atomic distance of $d_{(622)}=3.7 \AA$ and $d_{(222)}=7.1 \AA$ found in all samples and in agreement with the XRD pattern of 
zeolite (Figure 1a). The interplanar distances for maghemite phase were found to be $d_{(220)}=2.9 \AA$, $d_{(111)}=4.8 \AA$, and $d_{(311)}=2.5 \AA$, respectively.
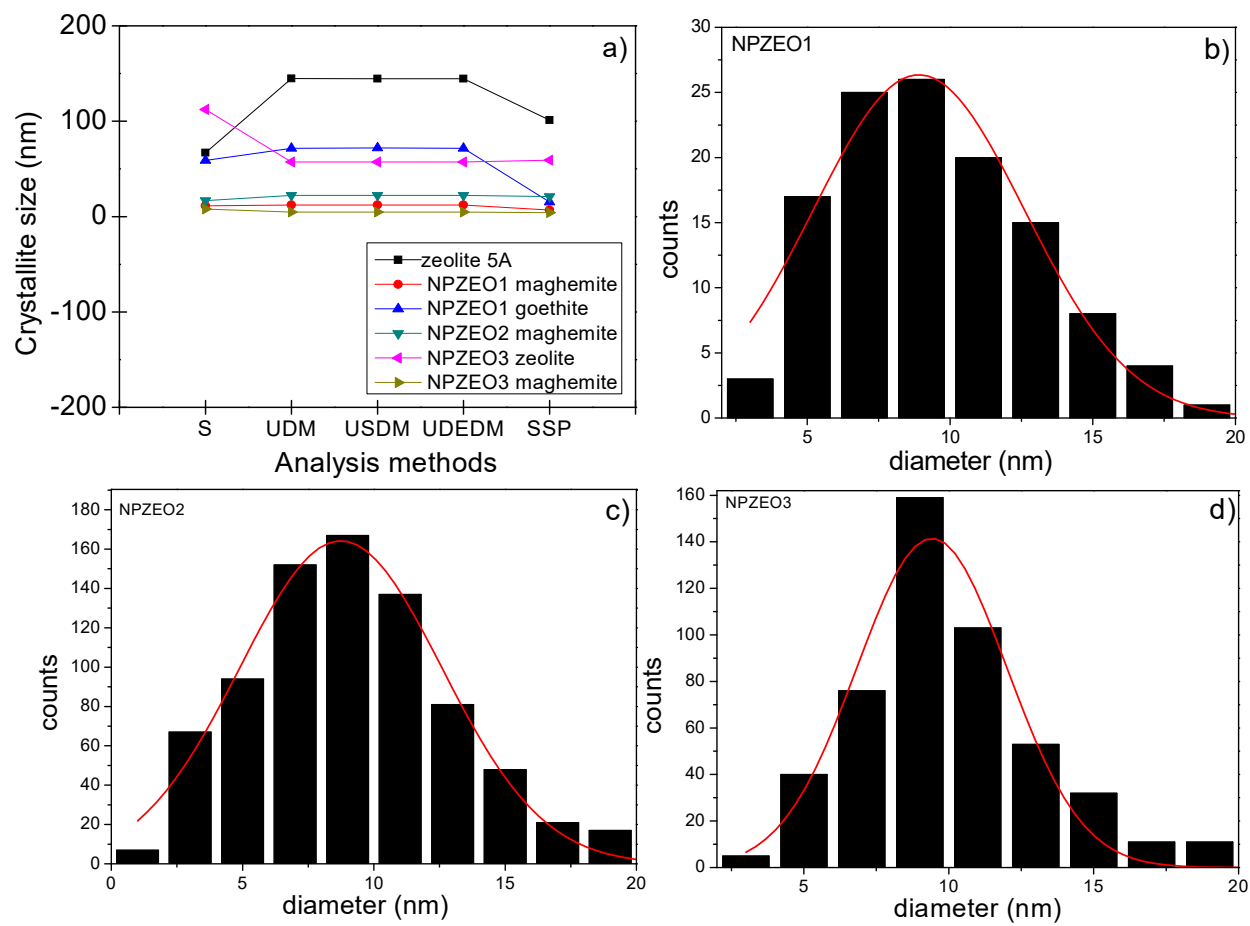

Figure 3. Crystallite size achieved by the analysis methods for all samples (a). Particle size distribution for the NPZEO1 (b), NPZEO2 (c), and NPZEO3 (d) samples.

\subsection{Surface and Textural Properties}

$\mathrm{N}_{2}$ adsorption-desorption isotherms determined at $77 \mathrm{~K}$ and pore size distributions, calculated by the NLDFT method, of magnetic zeolite nanocomposites are shown in Figure 4a,b, respectively. The textural properties, including specific BET surface area, pore volume, and pore width, are given in Table 2. The isotherms are classified as type IV, according to International Union of Pure and Applied Chemistry (IUPAC) classification for mesoporous adsorbents [32]. The $\gamma-\mathrm{Fe}_{2} \mathrm{O}_{3} \mathrm{NPs}(9 \mathrm{~nm}$ in size) often present a low BET surface area of $88 \mathrm{~m}^{2} / \mathrm{g}$ [29]. So, in our case, we observed an enhancement of surface area up to $194 \mathrm{~m}^{2} / \mathrm{g}$; an effect that can be explained by the presence of zeolite type $5 \mathrm{~A}$ $\left(571 \mathrm{~m}^{2} / \mathrm{g}\right)$. As a consequence, it gives more available sites to the whole material to adsorb and remove the lead cations. It is worth mentioning that the high value of surface BET area of the zeolite 5A is related to its microporosity $\left(0.18 \mathrm{~cm}^{3} / \mathrm{g}\right)$ and additional mesoporosity $\left(0.06 \mathrm{~cm}^{3} / \mathrm{g}\right)$, as indicated in Table 2 [33]. The values of pore volume $\left(\sim 0.35\right.$ to $\left.0.40 \mathrm{~cm}^{3} / \mathrm{g}\right)$ for the NPZEO1 and NPZEO2 samples are similar to those found in graphene matrix loading high iron oxide NPs (ca. 6-10 nm) [34], with relative amounts of iron precursors used in the synthesis. The amount of adsorption for the NPZEO2 sample is significantly lower than those for the other two samples, but it is not reflected in the pore volume of the NPZEO2 sample. This effect may be related to the blocking of pore entrance or reduction of the free volume inside pores. Additionally, the NPZEO3 sample exhibited less pore volume $\left(0.13 \mathrm{~cm}^{3} / \mathrm{g}\right)$, close to the pure zeolite, confirming the major contribution of zeolite on this sample. 

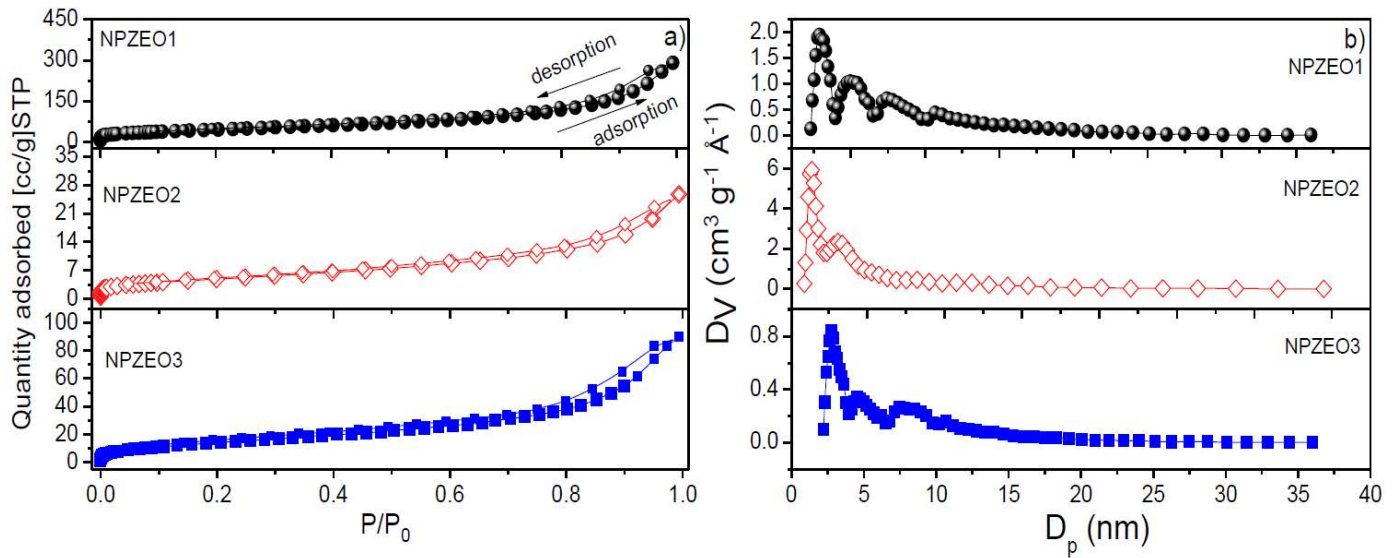

Figure 4. $\mathrm{N}_{2}$ adsorption-desorption isotherms (a) and pore size distribution (PSD) (b) for NPZEO1, NPZEO2, and NPZEO3 samples.

Table 2. Textural parameters obtained for zeolite Type 5A, NPZEO1, NPZEO2, and NPZEO3 adsorbents. BET, Brunauer-Emmett-Teller.

\begin{tabular}{|c|c|c|c|}
\hline Adsorbent & BET Surface Area $\left(\mathrm{m}^{2} / \mathrm{g}\right)$ & Pore Volume $\left(\mathrm{cm}^{3} / \mathrm{g}\right)$ & Pore Width (nm) \\
\hline zeolite type 5A [33] & 571 & 0.18 & 0.5 \\
\hline NPZEO1 & 167 & 0.40 & 3.2 \\
\hline NPZEO2 & 178 & 0.35 & 1.4 \\
\hline NPZEO3 & 194 & 0.13 & 2.8 \\
\hline
\end{tabular}

\subsection{Magnetic Properties}

The M-H loops for the NPZEO1, NPZEO2, and NPZEO3 samples are shown in Figure 5a. The saturation magnetizations $\left(\mathrm{M}_{\mathrm{S}}\right)$ at RT for the NPZEO1 and NPZEO3 samples have values of $\sim 30 \mathrm{emu} / \mathrm{gFe}$, while the NPZEO2 sample has $36 \mathrm{emu} / \mathrm{gFe}$; that is, $\mathrm{M}_{\mathrm{s}}$ values of our samples are smaller than $60 \mathrm{emu} / \mathrm{gFe}$ reported for pure $\gamma-\mathrm{Fe}_{2} \mathrm{O}_{3} \mathrm{NPs}$ [29]. The $\mathrm{M}_{\mathrm{s}}$ value reduction is also consistent with their particle size distributions, as shown by their TEM histograms (the three samples have close particle sizes between 8 and $9 \mathrm{~nm}$ ). In addition, different experimental methods result in different particle morphologies, so, a good explanation for a reduction of $\mathrm{M}_{\mathrm{s}}$ relative to the pure $\gamma-\mathrm{Fe}_{2} \mathrm{O}_{3} \mathrm{NPs}$ is the enhancement of the surface magnetic disorder of our samples and, consequently, low magnetization owing to magnetic frustration (magnetic dead-like layer) [29,31]. The remanent moments have values of 4.3 (3), 7.6 (3), and 3.7 (3) emu/g and the coercive fields have close values of 260 (5) Oe for all the samples. The thermal dependence of the susceptibility M-T is given in Figure 5b. The ZFC and FC signals revealed a magnetic blocked behavior near RT for the three samples. The shapes of M-T curves (ZFC and FC) suggest that our samples have a broad particle distribution, as observed by TEM images, and as expected owing to the chemical co-precipitation method. The nanocomposites were tested under applied field to guarantee that they are suitable for magnetic remediation, as a magnetic dead-layer could reduce its applicability, and we observed that the nanocomposites are well sensitive to the external field yielded by permanent magnets. The magnetic properties presented by the samples guaranteed a good magnetic removal performance, as will be discussed in the next section. 

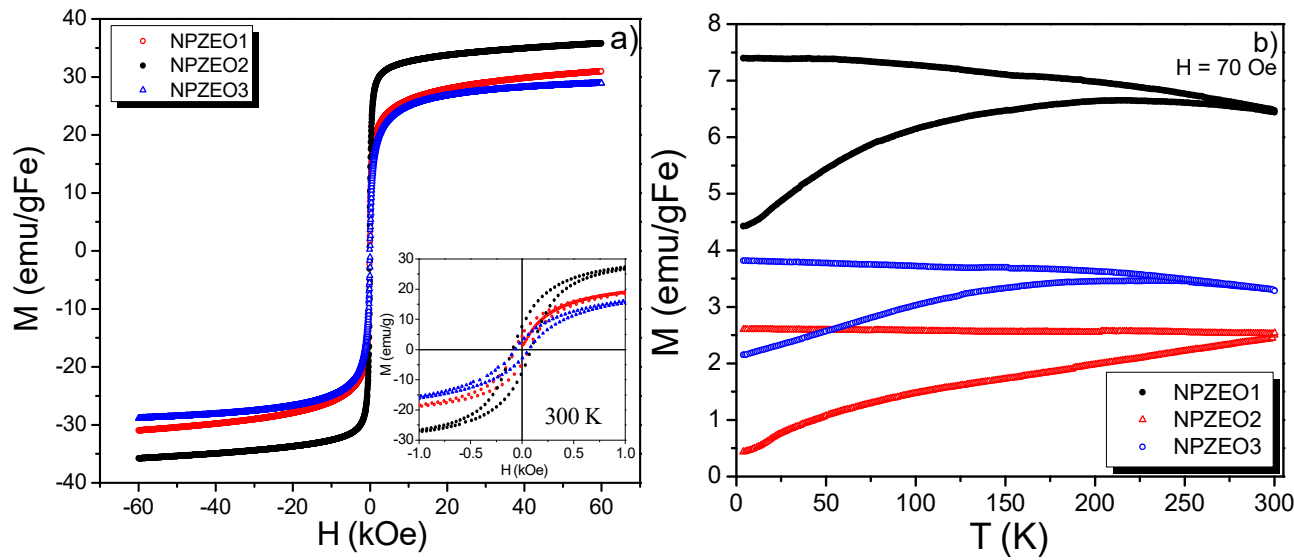

Figure 5. $\mathrm{M}-\mathrm{H}$ loops recorded at $300 \mathrm{~K}$ (a) and zero field cooling (ZFC) and field cooling (FC) measurements (b) for NPZEO1, NPZEO2, and NPZEO3 samples. The inset in (a) is a magnification of the $\mathrm{M}-\mathrm{H}$ loop in the region -1 to $+1 \mathrm{kOe}$.

\subsection{Effect of Variable Parameters on the Pb (II) Adsorption Process}

Before conducting in detail adsorption studies, the adsorption kinetic performance at $\mathrm{pH}=6$ and $300 \mathrm{~K}$ was tested for the three synthesized samples (see Figure 6a) with the aim of finding the highest removal efficiency among the studied adsorbents. The removal efficiency was calculated by the following:

$$
R(\%)=\frac{C_{0}-C_{f}}{C_{0}} \times 100 \%
$$

We checked that the NPZEO1 and NPZEO2 samples have shown less removal efficiency, as compared with the NPZEO3 sample; an effect that was mainly attributed to the high iron oxide content present in the first two samples. As our aim was to find an adsorbent with remarkable adsorption and magnetic separation properties, we selected the NPZEO3 sample for more detailed and systematic adsorption studies.
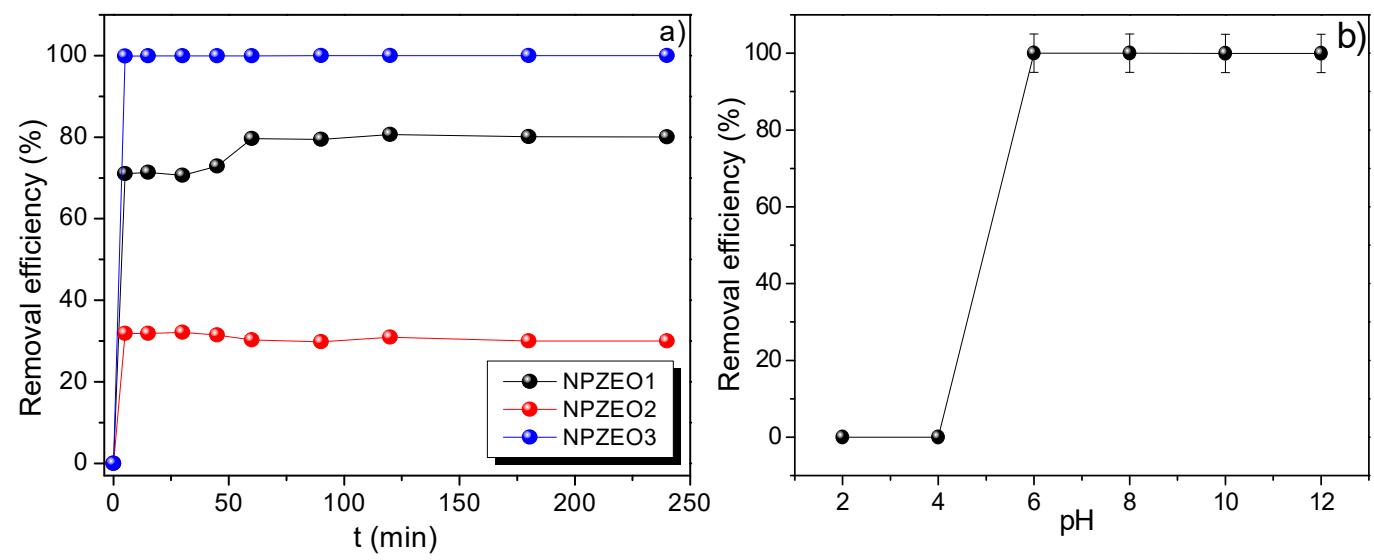

Figure 6. $\mathrm{Pb}$ (II) adsorption kinetic curves obtained for NPZEO1, NPZEO2, and NPZEO3 samples (a). $\mathrm{pH}$ dependence of the removal efficiency for sample NPZEO3 (b).

\subsection{Effect of $\mathrm{pH}$ and Adsorption Mechanism}

The $\mathrm{pH}$ dependence of the adsorbed amount is shown in Figure 6b. It can be clearly observed that the adsorption efficiency is sensitive to $\mathrm{pH}$ changes. Specifically, at low $\mathrm{pH}$ values $(<4)$, the removal capacity of $\mathrm{Pb}(\mathrm{II})$ is relatively low. This can be explained if one considers repulsive electrostatic forces between the protonated surface of maghemite $\left(\mathrm{Fe}-\mathrm{OH}_{2}^{+}\right)$and the metal lead cations. The same tendency at low $\mathrm{pH}$ was also reported in recent works for divalent ions [16,35]. For $\mathrm{pH}>5$, the removal efficiency 
is significantly increased to $99.9 \%$, a value that is kept unchanged for high alkaline intervals. At high $\mathrm{pH}$ values $(\sim 10)$, the NPs surfaces are coated with negative hydroxyl groups $\left(\equiv \mathrm{FeOH} \rightleftharpoons \mathrm{FeO}^{-}+H^{+}\right)$, by which exchange of metal ions with $\mathrm{H}^{+}$is favored at the NPs surface [10]. In addition, the zeolite type $5 \mathrm{~A}$ can also play an important role in the adsorption enhancement owing to the cation exchange interaction between $\mathrm{Pb}^{2+}$ and $\mathrm{Ca}^{2+}$ in the dehydrated $\mathrm{Ca}-\mathrm{A}$ zeolite framework. A representative scheme that describes the mechanism for the lead adsorption in our composites is given in Figure 7.

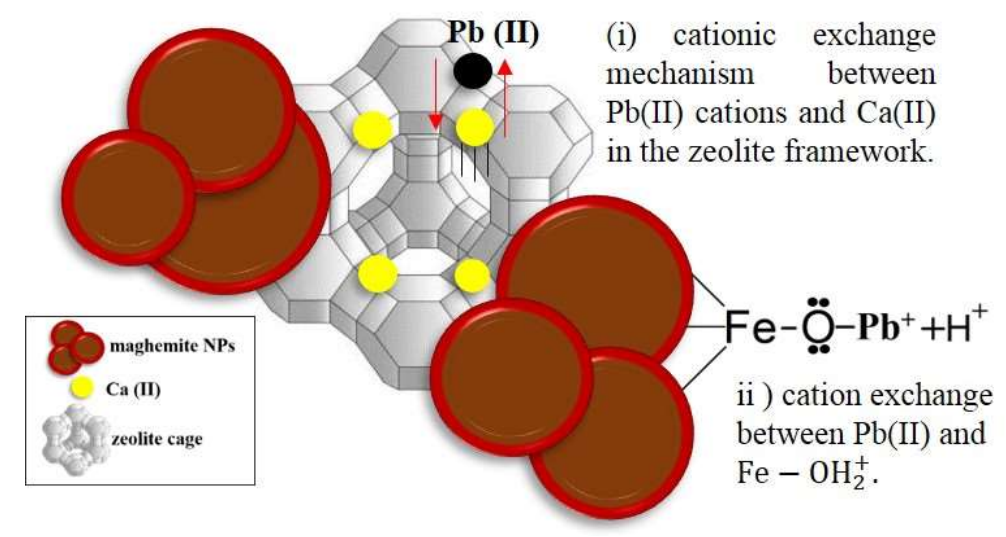

Figure 7. Proposed scheme to describe the mechanism for the $\mathrm{Pb}(\mathrm{II})$ adsorption using the NPZEO3 sample as adsorbent. Notice that maghemite nanoparticles (NPs) have a size distribution and sizes that are bigger than zeolite cages.

\subsection{Effect of the Amount of NPZEO3 on the Adsorption Process}

The effect of the NPZEO3 dosage in the adsorbed amount was studied and the results are plotted in Figure 8. We can observe that the adsorbed amount increases with the increasing adsorbent mass and reaches a plateau at $15 \mathrm{mg}$. The agitation speed was another variable parameter studied in our work. We can clearly distinguish from Figure S6 that the removal efficiency of $100 \%$ is speed agitation independent, which is good for technological purposes, because in big baths, it is quite difficult to guarantee homogeneous agitation of an effluent.

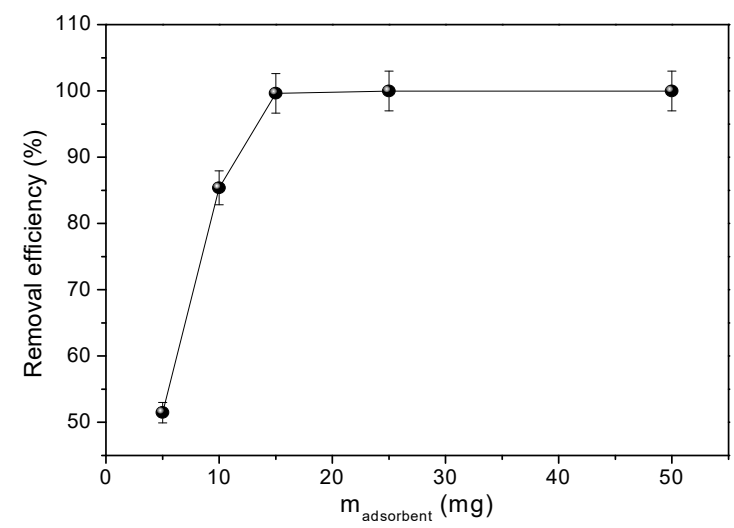

Figure 8. Adsorbent mass dependence of the removal efficiency $C_{0}=70 \mathrm{mg} \mathrm{L}^{-1}$.

\subsection{Adsorption Kinetics}

Figure $9 a, b$ show the adsorption kinetic profile of the zeolite type 5A and NPZEO3 for an interval of $5 \mathrm{~min}$ to $4 \mathrm{~h}$. To decrease the level of pollution and to enhance potential applications of the materials, the tests of lead adsorption and magnetic removal must be done in a shortest time. From these kinetic curves, it can be noted that the equilibrium time is quickly reached in $5 \mathrm{~min}$ for the NPZEO3 sample. To our knowledge, this time is the smallest equilibrium time reported in the literature as compared with several systems given in Table 3. 

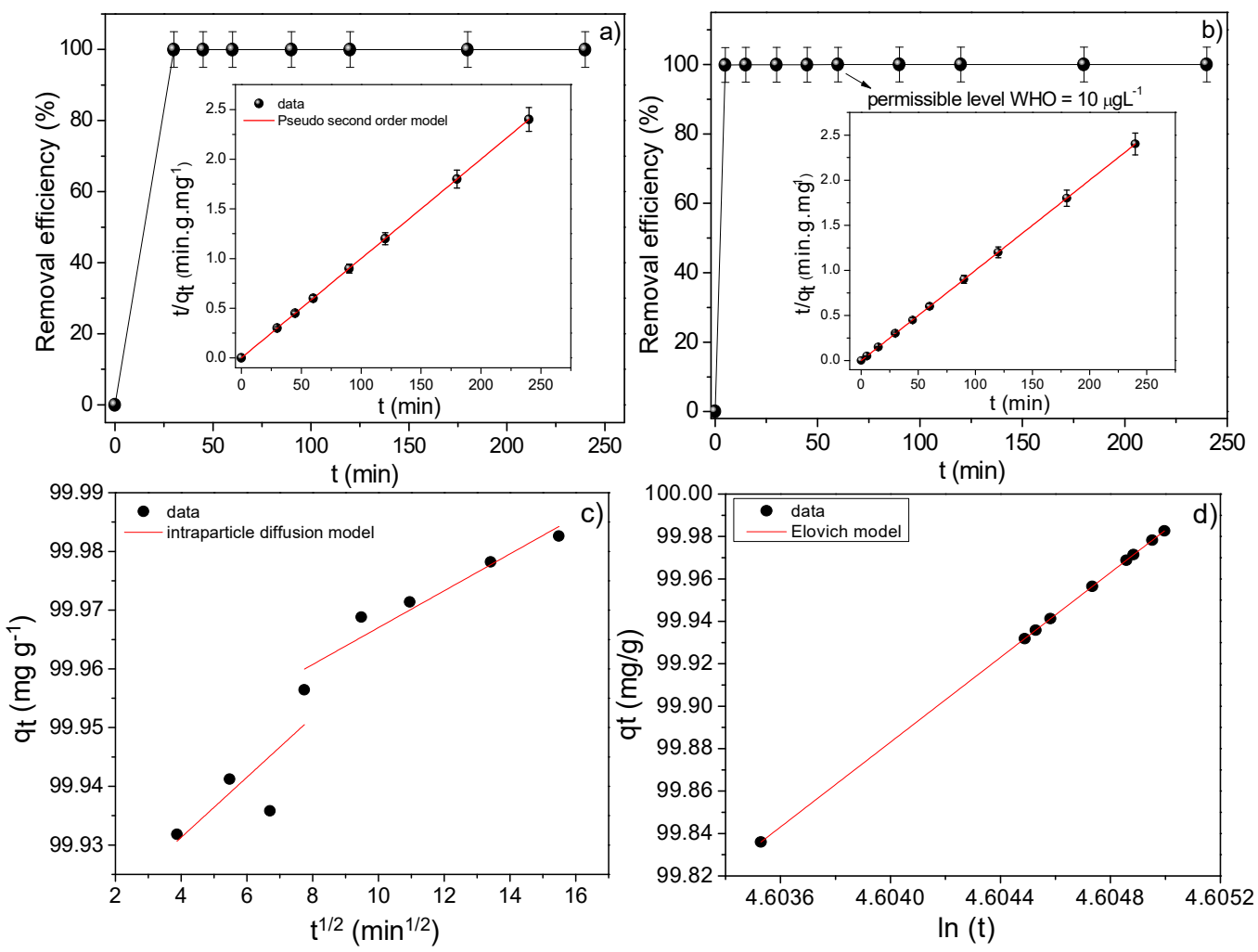

Figure 9. Time dependence of $\mathrm{Pb}$ (II) adsorption capacity for the zeolite type 5A (a) and NPZEO3 (b). The insets show the data fitted to the pseudo kinetic order model. Intraparticle diffusion model (c) and Elovich kinetic model (d) applied to the NPZEO3 sample are also displayed. WHO, World Health Organization.

Table 3. Adsorption kinetic parameters of several systems found in the literature given for comparison, where $t$ is the equilibrium time for adsorption. NPs, nanoparticles.

\begin{tabular}{|c|c|c|c|c|c|}
\hline Adsorbent & $k_{2}\left(\mathrm{mg} \mathrm{g}^{-1} \min ^{-1}\right)$ & $\mathrm{R}(\%)$ & $t$ (min) & $C_{0}\left(\mathrm{mg} \mathrm{L}^{-1}\right)$ & Dose $\left(\mathrm{g} \mathrm{L}^{-1}\right)$ \\
\hline $\mathrm{Co}-\mathrm{Fe}_{2} \mathrm{O}_{3}[16]$ & 1.74 & 95 & 45 & 20 & 0.1 \\
\hline ZIF-8@GO [35] & $5.89 \times 10^{-3}$ & - & 100 & 30 & 0.15 \\
\hline $\begin{array}{l}\text { MNPs@carboxymethylated } \\
\text { biopolymers [17] }\end{array}$ & $34 \times 10^{-3}$ & 99.9 & 180 & 24 & 2 \\
\hline $\begin{array}{c}\text { nanoscale zero-valent } \\
\text { irons (nZVI) [36] }\end{array}$ & $7.65 \times 10^{-4}$ & $\sim 90$ & 200 & 100 & 0.35 \\
\hline$\alpha-\mathrm{Fe}_{2} \mathrm{O}_{3}$ NPs [37] & $12 \times 10^{-4}$ & $\sim 88$ & 240 & 10 & 0.1 \\
\hline $\mathrm{Fe}_{3} \mathrm{O}_{4} @ S B A-15$ [38] & $11 \times 10^{-3}$ & - & 720 & & \\
\hline zeolite 5A (this work) & 35.5 & 100 & 15 & 50 & 0.5 \\
\hline NPZEO3 (this work) & 0.9 & 100 & 5 & 50 & 0.5 \\
\hline
\end{tabular}

In addition, our data have shown that the adsorbed amount reached a remarkable value of $99.99 \%$ in the first 5 min of contact time, with a reduction in the $\mathrm{Pb}$ (II) concentration from an initial concentration of $50 \mathrm{mg} \mathrm{L}^{-1}$ to $82 \mu \mathrm{g} \mathrm{L}^{-1}$. This demonstrates the high potential of our system to adsorb lead from $\mathrm{Pb}$-contaminated water. For immersion times higher than $30 \mathrm{~min}$, the concentrations are below the detection limit of ICP-OES equipment, $10.4 \mu \mathrm{g} \mathrm{L}{ }^{-1}$, which is the permissible concentration of lead in drinking water, according to WHO guidelines. Zeolite type $5 \mathrm{~A}$ is a remarkable adsorbent, as we demonstrated (after only $15 \mathrm{~min}$, it adsorbed all lead from water). However, it is necessary to have an adsorbent that can be easily removed from water, which is why we form a hybrid with maghemite to combine both adsorption and removal magnetic separation properties. The cost of combining both phases is a reduction in the kinetic rate constant, but it is still faster than other parent 
systems (Table 3), which are dominated by a slow $k_{2}$ value. The use of magnetic particles helps the entire process and improves technological applications where contaminants should be completely removed from the effluents (zeolites that are not removed will become a contaminant as well). Further, the adsorption kinetic behavior was studied using the following kinetic adsorption models given by Equations (16)-(18) [39]:

$$
\begin{aligned}
\frac{t}{q_{t}} & =\frac{1}{k_{2} q_{e}^{2}}+\frac{t}{q_{e}}(\text { Pseudo second order model }) \\
q_{t} & =k_{p} t^{1 / 2}+C(\text { intraparticle diffusion model }) \\
q_{t} & \left.=\frac{1}{\beta} \ln (\alpha \beta)+\frac{1}{\beta} \ln (t) \text { (Elovich kinetic model }\right)
\end{aligned}
$$

where $k_{2}\left(\mathrm{~g} \mathrm{mg}^{-1} \mathrm{~min}^{-1}\right)$ is the pseudo-second-order rate constant and $k_{2} q_{e}^{2}$ is the initial adsorption rate, $k_{p}$ relates the rate constant of intra-particle diffusion $\left(\mathrm{mg} \mathrm{g}^{-1} \mathrm{~m}^{-0.5}\right), \mathrm{C}$ corresponds to the boundary layer thickness, $\alpha$ is the initial adsorption rate $\left(\mathrm{mg} \mathrm{min}^{-1}\right)$ at $t=0$, and $\beta$ represents the surface coverage length and activated energy $\left(\mathrm{g} \mathrm{mg}^{-1}\right)$. By fitting the straight line of $\frac{t}{q_{t}}$ versus $t$, values of $\frac{1}{k_{2} q_{e}^{2}}$ as the intercept and $\frac{1}{q_{e}}$ as the slope were obtained (insets of Figure $\left.9 a, b\right)$. The value of $q_{e}$ was found to be equal to $100 \mathrm{mg} \mathrm{g}^{-1}$, which is identical to the experimental one. The $\mathrm{R}^{2}$ parameter had a value of 0.995 , which suggests that the kinetic adsorption process is governed by chemisorption of lead on zeolite type $5 \mathrm{~A}$ and in the composite. Moreover, the value of $k_{2}$ was equal to 35.5 and $0.9 \mathrm{~g} \mathrm{mg}^{-1} \mathrm{~min}^{-1}$ for the zeolite type 5A and NPZEO3 samples, respectively. The obtained values are bigger when compared with the parent systems used for lead adsorption, as shown in Table 3. When using the intraparticle diffusion model for the NPZEO3 sample, a two-step kinetic adsorption behavior is observed. The first step corresponds to the diffusion of $\mathrm{Pb}$ (II) through the solution to the adsorbent surface, whereas the second step is a slow adsorption stage related to intraparticle diffusion of $\mathrm{Pb}$ (II) cations through adsorbent's pores (in this case, the mesoporous of zeolite and maghemite). The obtained parameters, calculated by fitting Figure $9 \mathrm{c}$, gave values of $k_{p 1}=3 \times 10^{-3} \mathrm{mg} \mathrm{g}^{-1} \mathrm{~m}^{-0.5}, C_{1}=99.94 \mathrm{mg} \mathrm{g}^{-1}, \mathrm{R}^{2}=0.90$ and $k_{p 2}=5 \times 10^{-3} \mathrm{mg} \mathrm{g}^{-1} \mathrm{~m}^{-0.5}, C_{2}=99.91 \mathrm{mg} \mathrm{g}^{-1}, \mathrm{R}^{2}=0.90$. The plot (Figure $9 \mathrm{~d}$ ) of $q_{t}$ versus $\ln t$ has a good linear behavior with $R^{2}=0.999$. This means that the Elovich kinetic model fits well the adsorption data, in agreement with the pseudo-second-order model, that is, it confirms a chemisorption process. To find the best model that describes our kinetic adsorption data, we employed the AIC calculation given by Equation (2) [26], using the values of the Table 4, and we conclude that the intraparticle diffusion model better describes the kinetic adsorption behavior of $\mathrm{Pb}$ (II) onto the NPZEO3 surface. In this regard, the intraparticle diffusion kinetic model is preferable especially when using hybrids of porous/mesoporous material such as zeolite and maghemite NPs.

Table 4. Values of Akaike's information criterion (AIC) for the three kinetic adsorption models used in this work.

\begin{tabular}{cccc}
\hline Model & $\boldsymbol{q}_{t, \text { exp }}$ & $\boldsymbol{q}_{t, \text { model }}$ & AIC \\
\hline Pseudo second order model & 99.8 & 100 & -50.12 \\
Intraparticle difusion model & 99.8 & 99.91 & -40.28 \\
Elovich & 99.8 & 99.908 & -46.73 \\
\hline
\end{tabular}

\subsection{Adsorption Isotherm}

Figure 10 displays the adsorption isotherm obtained for the NPZEO3 sample at $\mathrm{pH}=5.5$. Three adsorption models [40] were used to study the adsorption process performed at the composite surface:

$$
\left.q_{e}=\frac{Q_{0} b C_{e}}{1+b C_{e}} \text { (Langmuir model }\right)
$$




$$
\begin{gathered}
q_{e}=K_{F} C_{e}^{1 / n} \text { (Freundlich model) } \\
q_{e}=\frac{q_{m_{S}} k_{S} C_{e}^{m_{S}}}{1+k_{S} C_{e}^{m_{S}}} \text { (Sips model) }
\end{gathered}
$$

where $q_{e}$ is the amount of adsorbate adsorbed per unit weight of adsorbent, $C_{e}\left(\mu g \mathrm{~L}^{-1}\right)$ is the equilibrium adsorbate concentration in the final solution, $Q_{0}$ is the maximum adsorption capacity $\left(\mathrm{mg} \mathrm{g}^{-1}\right), \mathrm{b}\left(\mathrm{mg}^{-1} \mathrm{~L}\right)$ is the Langmuir constant, $K_{F}\left(\mathrm{mg}^{1-\mathrm{n}} \mathrm{L}^{\mathrm{n}} / \mathrm{g}\right)$ and $1 / \mathrm{n}$ are assigned to the adsorption capacity and strength, $q_{m_{S}}\left(\mathrm{mg} \mathrm{g}^{-1}\right)$ is the Sips maximum adsorption capacity, $k_{S}\left(\mathrm{~L} \mathrm{mg}^{-1}\right)^{\mathrm{m}}$ the Sips equilibrium constant, and $\mathrm{m}_{S}$ is the Sips model exponent. The parameters obtained after fitting the isotherm data are summarized in Table 5. It can be seen that the Langmuir model gave a value of $Q_{0}=252$ (5) $\mathrm{mg} \mathrm{g}^{-1}$, which is a high value when compared with those reported in the literature $[16,17,36]$.

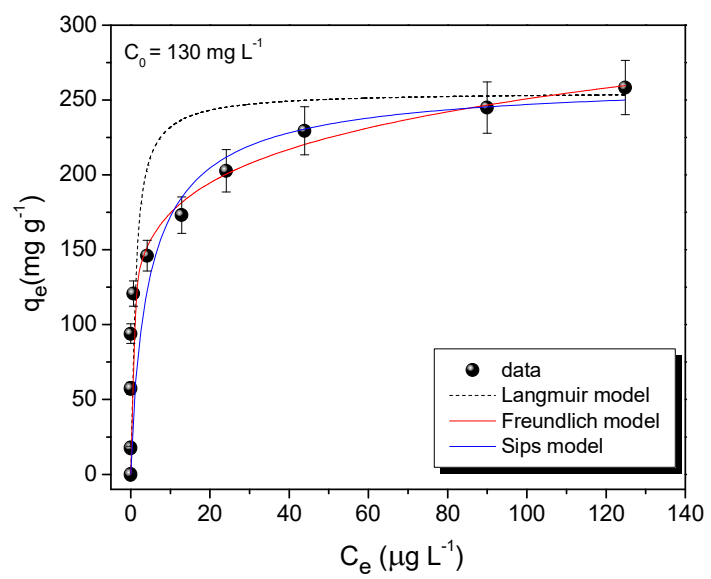

Figure 10. $\mathrm{Pb}(\mathrm{II})$ adsorption isotherm for NPZEO3 as adsorbent in $\mathrm{Pb}$-contaminated water.

Table 5. Parameters obtained from fitting the Langmuir, Freundlich, and Sips models to the experimental isotherm for $\mathrm{Pb}(\mathrm{II})$ adsorption.

\begin{tabular}{cccccc}
\hline \multicolumn{5}{c}{ Pb (II) Isotherm } \\
\hline \multicolumn{2}{c}{ Langmuir Parameters } & \multicolumn{2}{c}{ Freundlich Parameters } & \multicolumn{2}{c}{ Sips Parameters } \\
\hline$Q_{0}\left(\mathrm{mg} \mathrm{g}^{-1}\right)$ & $252(5)$ & $K_{F}\left(\mathrm{mg} \mathrm{g}^{-1}\right)$ & $122(5)$ & $q_{m_{S}}\left(\mathrm{mg} \mathrm{g}^{-1}\right)$ & $265(5)$ \\
$b\left(\mathrm{mg}^{-1} \mathrm{~L}\right)$ & $0.99(1)$ & $1 / n$ & $0.16(5)$ & $k_{S}\left(\mathrm{~L} \mathrm{mg}^{-1}\right)^{\mathrm{m}}$ & $0.25(5)$ \\
$\mathrm{R}^{2}$ & 0.88 & $\mathrm{R}^{2}$ & 0.97 & $m_{S}$ & $0.87(5)$ \\
& & & & $\mathrm{R}^{2}$ & 0.98 \\
\hline
\end{tabular}

However, the small value of $\mathrm{R}^{2}=0.88$ suggests that the adsorption process is not governed by monolayer covering. This is correlated to the non-saturation behavior in the high concentration range. Looking to the fitting parameters, obtained by the Freundlich and Sips methods, we concluded that the adsorption process occurs over a heterogeneous surface, where a finite maximum adsorption capacity value is not reached. The increment in the $q_{m_{S}}$ value, as compared with the value from the Langmuir method, suggests that our system can work successfully in higher Pb concentration ranges, providing wider usability for our magnetic composite adsorbent. The estimated AIC values of 27.9 and 31.9 for Sips and Langmuir models reinforce that the Sips model is the best model to describe our experimental data.

\subsection{Interferent Ions and Reusability}

A water sample under realistic conditions (effluents from industries, for example, mining tailings) presents additional divalent cations that can significantly affect the performance of the adsorbent to remove $\mathrm{Pb}(\mathrm{II})$. Therefore, adsorption experiments in the presence of other divalent cations, like $\mathrm{Ca}$ (II), 
$\mathrm{Cu}(\mathrm{II})$, and $\mathrm{Cd}(\mathrm{II})$, were also studied, and the results are shown in Figure 11a. It can be seen that the removal efficiency is not affected by the use of 0 to $1.0 \mathrm{mM}$ of $\mathrm{Ca}$ (II) and $\mathrm{Cu}$ (II). However, the use of $\mathrm{Cd}(1.0 \mathrm{mM})$ slightly decreases the removal efficiency from $99.9 \%$ to $88.2 \%$. To test the reuse of produced magnetic adsorbent of this work, we performed experiments (the results are shown in Figure 11b) with following the steps: after reaching the equilibrium time, the condensed material was separated by filtration and magnetic decantation and led to a treatment with $0.1 \mathrm{M} \mathrm{HCl}$ for $\mathrm{Pb}$ (II) desorption. Thereafter, repeated adsorption experiments were performed using an initial concentration of $70 \mathrm{mg} \mathrm{L}^{-1}$. Seven cycles were tested and the adsorption removal efficiency remained at about $82 \%$. Our results clearly demonstrate that the adsorption is quite stable and that the adsorbent NPZEO3 has remarkable power to be used more than once in a clear water process, that is, the results suggest that these materials have enhanced capabilities for technological applications as a magnetic remediation absorbent nanocomposite.
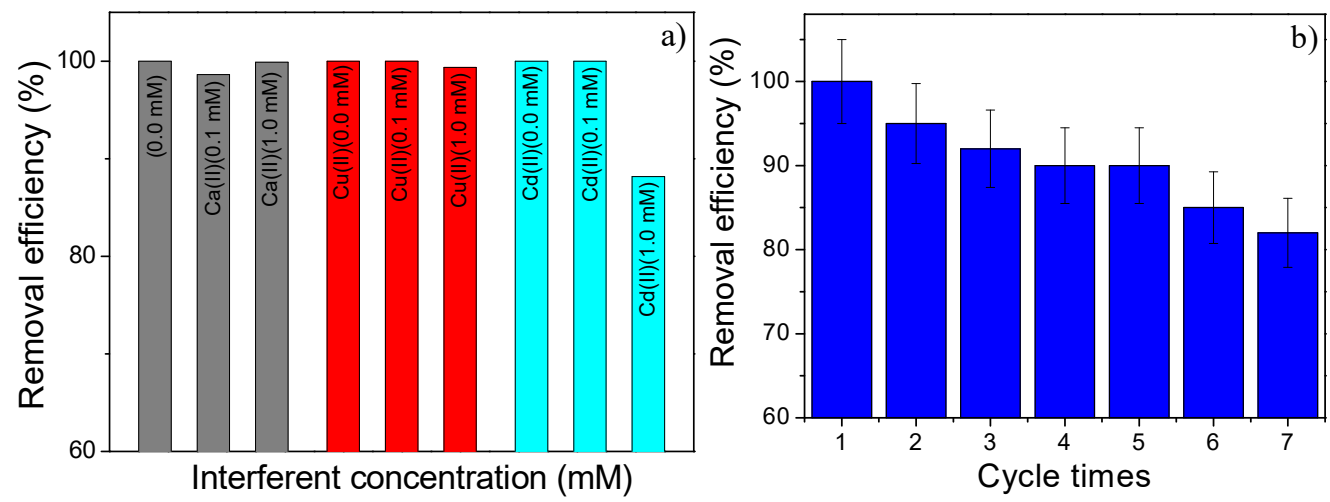

Figure 11. Effect of interfering divalent cations on the removal efficiency percentage (a) and recycling performance of the NPZEO3 sample as absorbent (b). $\mathrm{Pb}(\mathrm{II})$ initial concentration $=70 \mathrm{mg} \mathrm{L}^{-1}$.

\section{Conclusions}

Using the alkaline co-precipitation route, nanocomposites of maghemite and zeolite type 5A were successfully synthesized and used for the $\mathrm{Pb}(\mathrm{II})$ adsorption and magnetic removal process. Among the three synthesized systems with grain sizes from 7 to $11 \mathrm{~nm}$, the NPZEO3 sample showed the best adsorption performance with $99.99 \%$ removal efficiency. The adsorption kinetic experiments for the NPZEO3 sample show an enhanced equilibrium time of $5 \mathrm{~min}$, where $50 \mathrm{mg} \mathrm{L}^{-1} \mathrm{~Pb}$ (II) is totally removed from water by a permanent magnet that does not affect the magnetic response of the NPZEO3 sample. Further, the effects of variable parameters like adsorbent mass, agitation speed, and $\mathrm{pH}$ were systematically studied. Changes in the $\mathrm{pH}$ parameter allowed the study of the adsorption mechanism, where a cation exchange interaction was favored owing to the presence of $\mathrm{Ca}$ (II) in the zeolite framework and surface chemical configuration of the maghemite. Additionally, the adsorption isotherm data follow the Sips model, revealing that the system can be used for high $\mathrm{Pb}$ (II) concentrations, with an extrapolated value of $265 \mathrm{mg} \mathrm{g}^{-1}$ for $130 \mathrm{mg} \mathrm{L}^{-1}$ of initial concentration. Besides that, our sample revealed remarkable adsorption properties in the presence of interferent cations, such as $\mathrm{Ca}(\mathrm{II}), \mathrm{Cu}(\mathrm{II})$, and $\mathrm{Cd}(\mathrm{II})$. It has also been demonstrated that, after seven regeneration cycles, the efficiency for lead removal of the NPZEO3 sample was kept at $82 \%$, that is, it has excellent properties for the adsorption and removal of $\mathrm{Pb}(\mathrm{II})$. All three nanocomposites presented in this work are promising as adsorbent materials for water remediation processes.

\section{Patents}

The presented work is under request of patent with number 001335-2019/DIN, Indecopi-Peru. 
Supplementary Materials: The following are available online at http://www.mdpi.com/2079-4991/10/9/1668/s1, Figure S1: Scherrer plot; Figure S2: W-H plot; Figure S3: modified W-H plot; Figure S4: modified W-H plot; Figure S5: SSP plot; Figure S6: Speed agitation dependence of the removal efficiency; Table S1: Microstructural parameters.

Author Contributions: Data curation, J.A.R.-G. and K.T.; Investigation, J.A.R.-G., K.T., M.A.M.T., and E.S.; Writing-original draft, J.A.R.-G. and K.T.; Supervision, J.A.R.-G., E.C.P., and F.J.L.; Writing-review and editing, J.A.R.-G., K.T., M.A.S.J., E.S., M.A.M.T., E.C.P., and F.J.L. All authors have read and agreed to the published version of the manuscript.

Funding: The authors thank the following institutions for financial support: National University of San Marcos, CONCYTEC, FAPES, CAPES, CNPq, and UFES.

Conflicts of Interest: The authors declare no conflict of interest.

\section{References}

1. Singh, S.; Barick, K.C.; Bahadur, D. Functional Oxide Nanomaterials and Nanocomposites for the Removal of Heavy Metals and Dyes. Nanomater. Nanotechnol. 2013, 3, 1-19. [CrossRef]

2. Lu, F.; Astruc, D. Nanomaterials for removal of toxic elements from water. Coord. Chem. Rev. 2018, 356, 147-164. [CrossRef]

3. World Health Organization. Lead in Drinking-Water: Background Document for Development of WHO Guidelines for Drinking-Water Quality; World Health Organization: Geneva, Switzerland, 2003.

4. Deng, X.; Lü, L.; Li, H.; Luo, F. The adsorption properties of $\mathrm{Pb}$ (II) and $\mathrm{Cd}(\mathrm{II})$ on functionalized graphene prepared by electrolysis method. J. Hazard. Mater. 2010, 183, 923-930. [CrossRef] [PubMed]

5. Sharma, S.K.; Petrusevski, B.; Amy, G. Chromium removal from water: A review. J. Water Supply Res. Technol. Aqua. 2008, 57, 541. [CrossRef]

6. Baig, S.A.; Sheng, T.; Zhu, J.; Xu, X. Performance of an Integrated Treatment System for Clean Drinking Water Production. CLEAN Soil Air Water. 2015, 43, 13-26. [CrossRef]

7. Reviews in Mineralogy and Geochemistry. In Natural Zeolites: Occurrence, Properties, Applications; Bish, D.L.; Ming, D.W. (Eds.) Mineralogical Society of America: Washington, DC, USA, 2001; ISBN 0-939950-57-X.

8. Yang, R.T. Nanostructured adsorbents. Nanostructured Materials; Academic Press: Cambridge, MA, USA, 2001; p. 96, ISBN 0-12-008527-5.

9. Jiang, N.; Shang, R.; Heijman, S.G.J.; Rietveld, L.C. High-silica zeolites for adsorption of organic micro-pollutants in water treatment: A review. Water Res. 2018, 144, 145-161. [CrossRef] [PubMed]

10. Kumari, M.; Pittman, C.U.; Mohan, D. Heavy metals [chromium (VI) and lead (II)] removal from water using mesoporous magnetite (Fe3O4) nanospheres. J. Colloid Interface Sci. 2015, 442, 120-132. [CrossRef]

11. Mohammed, L.; Gomaa, H.G.; Ragab, D.; Zhu, J. Magnetic nanoparticles for environmental and biomedical applications: A review. Particuology 2017, 30,1-14. [CrossRef]

12. Irawan, C.; Nata, I.F.; Lee, C.-K. Removal of $\mathrm{Pb}(\mathrm{II})$ and $\mathrm{As}(\mathrm{V})$ using magnetic nanoparticles coated montmorillonite via one-pot solvothermal reaction as adsorbent. J. Environ. Chem. Eng. 2019, 7, 103000. [CrossRef]

13. Levin, C.S.; Hofmann, C.; Ali, T.A.; Kelly, A.T.; Morosan, E.; Nordlander, P.; Whitmire, K.H.; Halas, N.J. Magnetic-Plasmonic-core-shell nanoparticles. ACS Nano 2009, 3, 1379-1388. [CrossRef]

14. Eljamal, O.; Shubair, T.; Tahara, A.; Sugihara, Y.; Matsunaga, N. Iron based nanoparticles-zeolite composites for the removal of cesium from aqueous solutions. J. Mol. Liq. 2019, 277, 613-623. [CrossRef]

15. Eljamal, O.; Sasaki, K.; Hirajima, T. Sorption kinetic of arsenate as water contaminant on zero valent iron. JWARP 2013, 5, 563-567. [CrossRef]

16. Chen, W.; Lu, Z.; Xiao, B.; Gu, P.; Yao, W.; Xing, J.; Asiri, A.M.; Alamry, K.A.; Wang, X.; Wang, S. Enhanced removal of lead ions from aqueous solution by iron oxide nanomaterials with cobalt and nickel doping. J. Clean. Prod. 2019, 211, 1250-1258. [CrossRef]

17. Perez, T.; Pasquini, D.; de Faria Lima, A.; Rosa, E.V.; Sousa, M.H.; Cerqueira, D.A.; de Morais, L.C. Efficient removal of lead ions from water by magnetic nanosorbents based on manganese ferrite nanoparticles capped with thin layers of modified biopolymers. J. Environ. Chem. Eng. 2019, 7, 102892. [CrossRef]

18. Abdullah, N.H.; Shameli, K.; Abdullah, E.C.; Abdullah, L.C. Solid matrices for fabrication of magnetic iron oxide nanocomposites: Synthesis, properties, and application for the adsorption of heavy metal ions and dyes. Compos. Part. B Eng. 2019, 162, 538-568. [CrossRef] 
19. Match-Phase Identification from Powder Diffraction-Version 3, Crystal Impact-Dr. H. Putz; Dr. K. Brandenburg GbR, Kreuzherrenstr. 102, 53227 Bonn Germany. Available online: http://www.crystalimpact.com/match (accessed on 8 April 2020).

20. Pecharromán, C.; Gonzalez-Carreno, T.; Iglesias, J.E. The infrared dielectric properties of maghemite, $\gamma$ - $\mathrm{Fe}_{2} \mathrm{O}_{3}$, from reflectance measurement on pressed powders. Phys. Chem. Miner. 1995, 22, 21-29. [CrossRef]

21. Gualtieri, A.F.; Venturelli, P. In situ study of the goethite-hematite phase transformation by real time synchrotron powder diffraction. Am. Mineral. 1999, 84, 895-904. [CrossRef]

22. Porcher, F.; Souhassou, M.; Graafsma, H.; Puig-Molina, A.; Dusausoy, Y.; Lecomte, C. Refinement of framework disorder in dehydrated CaA zeolite from single-crystal synchrotron data. Acta Crystallogr. Sect. B Struct. Sci. 2000, 56, 766-772. [CrossRef] [PubMed]

23. Rodríguez-Carvajal, J. Software Manual: An Introduction to the Program FullProf 2000 (Version July 2001). 2001. Available online: https://www.psi.ch/sites/default/files/import/sinq/dmc/ManualsEN/fullprof.pdf (accessed on 8 April 2020).

24. Maamoun, I.; Eljamal, O.; Eljamal, R.; Falyouna, O.; Sugihara, Y. Promoting aqueous and transport characteristics of highly reactive nanoscale zerovalent iron via different layered hydroxide coatings. Appl. Surf. Sci. 2020, 506, 145018. [CrossRef]

25. Lowell, S.; Shields, J.E.; Thomas, M.A.; Thommes, M. Characterization of Porous Solids and Powders: Surface Area, Pore Size and Density; Science+Business Media: New York, NY, USA, 2004; ISBN 978-90-481-6633-6.

26. Falyouna, O.; Eljamal, O.; Maamoun, I.; Tahara, A.; Sugihara, Y. Magnetic zeolite synthesis for efficient removal of cesium in a lab-scale continuous treatment system. J. Colloid Interface Sci. 2020, 571, 66-79. [CrossRef] [PubMed]

27. Zak, A.K.; Majid, W.H.A.; Abrishami, M.E.; Yousefi, R. X-ray analysis of ZnO nanoparticles by Williamson Hall and size-strain plot methods. Solid State Sci. 2011, 13, 251-256.

28. Jamal, M.; Asadabadi, S.J.; Ahmad, I.; Aliabad, H.A.R. Elastic constants of cubic crystals. Comput. Mater. Sci. 2014, 95, 592-599.

29. Guivar, J.A.R.; Sadrollahi, E.; Menzel, D.; Fernandes, E.G.R.; López, E.O.; Torres, M.M.; Arsuaga, J.M.; Arencibia, A.; Litterst, F.J. Magnetic, structural and surface properties of functionalized maghemite nanoparticles for copper and lead adsorption. RSC Adv. 2017, 7, 28763-28779. [CrossRef]

30. Maamoun, I.; Eljamal, O.; Falyouna, O.; Eljamal, R.; Sugihara, Y. Stimulating effect of magnesium hydroxide on aqueous characteristics of iron nanocomposites. Water Sci. Technol. 2019, 80, 1996-2002. [CrossRef] [PubMed]

31. Guivar, J.A.R.; Sanches, E.A.; Bruns, F.; Sadrollahi, E.; Morales, M.A.; López, E.O.; Litterst, F.J. Vacancy ordered $\gamma-\mathrm{Fe}_{2} \mathrm{O}_{3}$ nanoparticles with nanohydroxyapatite: XRD, FTIR, XPS and Mössbauer studies. Appl. Surf. Sci. 2016, 389, 721-734. [CrossRef]

32. Thommes, M.; Kaneko, K.; Neimark, A.V.; Olivier, J.P.; Rodriguez-Reinoso, F.; Rouquerol, J.; Sing, K.S. Physisorption of gases, with special reference to the evaluation of surface area and pore size distribution (IUPAC Technical Report). Pure Appl. Chem. 2015, 87, 1051. [CrossRef]

33. Hamed, H.H. Oxygen separation from air using zeolite type 5A. Int. J. Sci. Eng. Res. 2015, 6, 597-602.

34. Guivar, J.A.R.; Bustamante, A.; Gonzalez, J.C.; Sanches, E.A.; Morales, M.A.; Raez, J.M.; López-Muñoz, M.-J.; Arencibia, A. Adsorption of arsenite and arsenate on binary and ternary magnetic nanocomposites with high iron oxide content. Appl. Surf. Sci. 2018, 454, 87-100. [CrossRef]

35. Wang, J.; Li, Y.; Lv, Z.; Xie, Y.; Shu, J.; Alsaedi, A.; Hayat, T.; Chen, C. Exploration of the adsorption performance and mechanism of zeolitic imidazolate framework-8@graphene oxide for $\mathrm{Pb}$ (II) and 1-naphthylamine from aqueous solution. J. Colloid Interface Sci. 2019, 542, 410-420. [CrossRef] [PubMed]

36. Dongsheng, Z.; Wenqiang, G.; Guozhang, C.; Shuai, L.; Weizhou, J.; Youzhi, L. Removal of heavy metal lead(II) using nanoscale zero-valent iron with different preservation methods. Adv. Powder Technol. 2019, 30, 581-589. [CrossRef]

37. Hashemzadeh, M.; Nilchi, A.; Hassani, A.H. Synthesis of novel surface-modified hematite nanoparticles for lead ions removal from aqueous solution. Mater. Chem. Phys. 2019, 227, 279-290. [CrossRef]

38. Wang, S.; Wang, K.; Dai, C.; Shi, H.; Li, J. Adsorption of $\mathrm{Pb}^{2+}$ on amino-functionalized core-shell magnetic mesoporous SBA-15 silica composite. Chem. Eng. J. 2015, 262, 897-903. [CrossRef] 
39. Simonin, J.P. On the comparison of pseudo-first order and pseudo-second order rate laws in the modeling of adsorption kinetics. Chem. Eng. J. 2016, 300, 254-263. [CrossRef]

40. Limousin, G.; Gaudet, J.P.; Charlet, L.; Szenknect, S.; Barthes, V.; Krimissa, M. Sorption isotherms: A review on physical bases, modeling and measurement. Appl. Geochem. 2007, 22, 249-275. [CrossRef]

(C) 2020 by the authors. Licensee MDPI, Basel, Switzerland. This article is an open access article distributed under the terms and conditions of the Creative Commons Attribution (CC BY) license (http://creativecommons.org/licenses/by/4.0/). 